\title{
Annual Company Reports' narratives migrate to the Web: A diachronic perspective
}

\begin{abstract}
Despite the dramatic innovation brought about in the field of corporate communication by the advent of the World Wide Web, when it comes to annual company reports (ACRs), companies seem to introduce few innovative digital elements in the drafting and formatting of the narrative sections. The present study, as the last step of a long-term research project, aimed at investigating this genre from a diachronic point of view by concentrating on the transformations that ACRs' corporate narratives undergo once they migrate to the Web. Two standpoints emerge: the first sees companies that are highly engaged in the digital environment take advantage of several digital tools at once, while the second proposes a slightly less technological approach whereby simple ACRs in pdf format are uploaded on the company website therefore lacking the most interactive functions. While radical changes in the presentation of ACRs' narratives between 2000 and 2018 cannot be traced, some companies have decided to deal with such narratives by reporting either the complete narrative or its synthesis.
\end{abstract}

Keywords: annual company report, corporate narrative, digital environment, genre theory, diachronic perspective.

\section{Introduction}

The Internet, which was already being used by $80 \%$ of US and European listed companies ten years ago (Dunne \& Morris 2009: 370) has become the main medium for the dissemination of financial information. Since the mid-1990s in fact, company websites have been crucial in shaping consumer perceptions (Crawford Camiciottoli 2019: 20). Indeed, printed grey literature has progressively been transferred to the virtual environment, allowing companies to both toss paper formats and also reach the lay public, who can now easily access corporate documents from a company's website. This, however, raises questions on companies' best practices, and long-term standards that ultimately lead to issues regarding companies' reliability, credibility, transparency, and trustworthiness. The use of the Web can potentially alter users' perception of corporate

1 Address for correspondence: Department of Political Sciences, Università di Roma "La Sapienza" Piazzale Aldo Moro 5, 00185 Rome, Italy. Email: cinzia.giglioni@uniroma1.it 
discourse, as they are no longer passive recipients but rather proactive pursuers of information (Madhavaram \& Appan 2010).

Based on Bhatia's definition of Critical Genre Analysis's aims, this study intends to move from text to context in order to enhance the understanding of the nature and function of corporate discursive practices (Bhatia 1996: 40). This paper represents the last step of a long-term research project on annual company reports (ACRs), which have been a fruitful field of investigation for business-oriented scholars and linguists alike. The drafting of ACRs' narrative sections (Chairman and CEO's messages) has varied over time, in response to changes in communicative circumstances, and their value has been well documented (Rutherford 2002; Beattie et al. 2004).

Drawing from Ware and Linkugel's (1973) definition of apologetic strategies - i.e. transcendence, denial, differentiation, bolstering - this long-term project explored strategies' use and distribution in ACRs (Giglioni 2014). Results showed that companies' poor performance is generally associated to the use of all four strategies (Giglioni 2017: 33). By adopting a diachronic perspective, this last phase of the research project intended to analyze the implementation of apologetic strategies in online ACRs' narratives. However, after a preliminary survey, which shed light on the companies' attitude towards the new digital environment, the purpose had to be adjusted. As a matter of fact, when companies transfer ACRs to the digital medium, they display a common tendency: they avoid introducing radical changes and thus tend to replicate the ACR's hard copy format. Nevertheless, at this point of the research, it was important to understand if all companies under analysis behave uniformly.

The 2000-2010 decade was crucial for communicative practices in professional settings due to the massive spread of the Web as a collaborative environment. In the decade that followed, ACRs were expected to follow a trend when transferred to the digital environment. Consequently, this paper aims at exploring how companies took advantage of web-based communication within a diachronic perspective.

The corpus (see section 3 ) of the present study consists of the narrative sections of six ACRs of the same number of companies, which are members of the FT30 index, that were retrieved in 2001, 2010, and 2019. ${ }^{2}$ Both the CEO and the Chairman's messages, in terms of digital elements, will be commented on. The research questions this study tries to answer are the following:

Q1: What is the company's procedure when transferring the ACR to the Web?

Q2: What do they want to achieve communicatively?

Q3: Have there been any significant changes over the last two decades?

2 ACRs are comprehensive reports on a company's activities, thus the year of publishing (and retrieval) is subsequent to the report's year of reference. Listed companies usually issue their ACRs in March. 


\section{Framework}

In 1973, the first International Accounting Standards Committee was established to harmonize accounting standards throughout European companies. In February 2009, the Financial Crisis Advisory Group was still discussing the topic (Chalmers et al. 2008). Nowadays, the International Financial Reporting Standards (IFRS) are recognized worldwide and employed by ACRs' drafters (Istrate \& Bogdan 2019). According to the IFRS (2018), ${ }^{3}$ which are standardized guidelines of describing a company's financial performance, the objective of financial reporting is "to provide financial information that is useful to users in making decisions relating to providing resources to the entity" (IFRS 2018: 15). While setting the principal standards and, by default, influencing the narratives it contains (see Tauringana \& Mangena 2006), this formalized communication system addresses an array of stakeholders, both internal (e.g. shareholders) and external (e.g. consumers). Formally, ACRs are divided into two separate sections, i.e. financial and narrative, the former reporting on a company's financial performance and the latter conveying a specific corporate narrative, which is ideally aimed to explain financial data. Balance sheets and non-narrative parts, in particular, are not reader-friendly, and the non-expert reader may actually feel overwhelmed by their figures and even by their so-called explanatory notes. Yet, implementing and meeting international standards, which are relevant for corporate communication in general and ACRs are no exception in this sense - become pivotal for all companies. Corporate communication, besides its functions, channels and processes, "is also an attitude or set of beliefs that people have about what and how to communicate and the inherent value of such efforts to communicate" (Argenti 2005: 358). Through ACR, transparency and comparability increase, and uncertainties about a company's future prospects decrease (Purver et al. 2018: 1).

Research on linguistic aspects of ACRs has become increasingly popular in the past two decades: for example, accounting narrative was used to shed light on language bias towards positive terms, namely the "Pollyanna effect"4 (Rutherford 2005); genre theory was applied to analyze macrostructure and visual elements (Ditlevsen 2012) identifying annual reports as statutory documents with different communicative purposes that reflect organizational changes; the macro analysis of key words and key semantic domains was complemented by close phraseological analyses to better understand the

3 The revised Conceptual Framework for Financial Reporting (Conceptual Framework) was issued in March 2018. While it was immediately effective for the International Accounting Standards Board (Board) and the IFRS Interpretations Committee, it will be effective for annual reporting periods beginning on or after 1 January 2020 in the case of companies that use the Conceptual Framework.

4 Rutherford conducted a corpus linguistics lexical analysis of British ACRs and was able to show how the language of ACRs is not neutral, rather it tends to descibe the company and its performance in positive terms. He named this aspect the"Pollyanna effect" (Rutherford 2005: 362). 
nuances of companies' messages (Murphy 2015); variation based on lexical and syntactic markers (Giglioni 2014) and the deployment of apologetic strategies in CEO and Chairman's statements (Giglioni 2017) established a clear connection between corporate narrative and a company's performance; vectors in distributed lexical representations (Purver et al. 2018) propose semantic associations between financial terms and their variation in time.

In light of the fact that rhetorical strategies are used and abused in corporate documents (Bhatia 2008: 166), a company's decision on how to adapt and customize its ACR based on the digital environment may be viewed as an attempt $\nabla$ or lack of thereof $\nabla$ to exploit it, and companies provide different reasons for developing corporate websites (Beatty et al. 2001). The relevant literature on pre-existing genres that are transferred to the virtual environment generally (Giltrow \& Stein 2009 inter alia) focuses on: extended participation that allows the general user to retrieve the report without having to be a shareholder; distribution in terms of speed and pervasiveness; use (and abuse) of multimodal content; and changes in communicative purposes.

\section{Corpus}

As the goal of the present paper is to carry out a diachronic analysis, the investigated corpus includes ACRs that had previously been studied in Giglioni (2017) and were issued in 2001 and 2010, as well as ACRs issued in 2019. The companies under examination are listed in the Financial Times index (FT 30), which is the oldest continuous index in the UK and is based on the share price of thirty British companies from a wide range of industries. In the original study, of these thirty companies, thirteen were not included in the index in 2009; one fund and three insurance companies were discarded due to their different accounting standards, and four had changed their name and probably suffered radical changes (e.g. mergers and acquisitions) by 2009. The ACRs of nine companies were then analyzed: British Petroleum (BP), British Airways (BA), British Telecom (BT), GNK (GNK), Invensys (INV), Marks \& Spencer (M\&S), Tale \& Lyle (T\&L), Tesco (TES), and Vodafone (VOD). By 2019, three of the remaining nine companies had undergone corporate changes: in 2011, International Consolidated Airlines Group replaced BA in the index; in 2018, GKN was taken over by Melrose Industries; in 2014, INV was acquired by Schneider Electric and was replaced by ARM Holdings, which was later (2016) taken over by Softbank and replaced by Associated British Foods (Table 1). 
Table 1. Corpus description ${ }^{5}$ - *ACRs' location on company websites in 2018

\begin{tabular}{|l|l|c|c|c|l|}
\hline & \multicolumn{1}{|c|}{ Sector } & $\mathbf{2 0 0 0}$ & $\mathbf{2 0 0 9}$ & $\mathbf{2 0 1 8}$ & \multicolumn{1}{|c|}{ Online location* } \\
\hline Company & \multicolumn{1}{|c|}{ Years } \\
\hline BP & Oil \& Gas & + & + & + & News\&Insights \\
\hline BA & Air transportation & + & + & -- & ---- \\
\hline BT & Telecommunications & + & + & + & Shares\&Performance \\
\hline GNK & Shipping and Trading & + & + & -- & ---- \\
\hline INV & $\begin{array}{l}\text { Engineering and } \\
\text { information technology }\end{array}$ & + & + & -- & ---- \\
\hline M\&S & $\begin{array}{l}\text { Clothing, home, food } \\
\text { products retailer }\end{array}$ & + & + & + & Investors \\
\hline T\&L & Food \& Beverage & + & + & + & Investors Hub \\
\hline TES & $\begin{array}{l}\text { Groceries / general } \\
\text { merchandise retailer }\end{array}$ & + & + & + & Investors \\
\hline VOD & Telecommunications & + & + & + & Investors\&Analysts \\
\hline
\end{tabular}

The present paper focuses on the statements of 18 Chairmen and CEOs in reference to 2000, 2009, and 2018. ${ }^{6}$ In addition, digital elements such as hyperlinks, videos, and interactive pdfs, are taken into account.

\section{ACRs migrate to the Web}

ACRs are easily downloadable documents of varying size that users can find on companies' websites or in pdf format by means of a quick search on a generic browser.

On the one hand, the World Wide Web has provided companies with the opportunity to present their viewpoints to an extensive audience, on the other hand it has also led to a loss of control over information dissemination (Ihator 2001). However, ACRs that are transferred to companies' websites could still be considered a form of controlled corporate communication. It has been observed that ACRs are generally transferred to the digital environment in a pdf, static format as part of a reproduction process (Garzone 2007:16), as a result, they are very similar to the version used in a non-digital environment, namely the hard copy. While this observation can be generally considered true, the present paper adds to it by claiming that some companies' decision to provide ACRs in a richer online format (web page) may have an impact on the disclosure of corporate

5 In the 'References' section of the present article, the links that are provided refer only to 2019. However, most websites have an 'Archive' section where documents from the previous years may be found.

6 As annual reports refer to the preceding financial year, the present corpus was retrieved from the companies' websites in 2001, 2010, and 2019. 
narratives. This is exemplified by the online, abridged version of the narrative sections, where companies purposely select what information to present to their readers.

In 2019, like in 2000 and 2009, two companies - BP and T\&L - invited users to download the company's ACR in pdf format, thus displaying a less technology-prone attitude. In 2019, in the 'News \& Insights' section of the website, BP provided an overview of the key activities and a link for both generic users and the company's shareholders, where they could receive a hard copy of it, free of charge, by contacting the designated office. Both the Chairman and the CEO's letters are separately downloadable (in pdf format) on the annual report's page.

BP's report increased in length, and a clear promotional style was adopted in its latest (2018) version. This ACR displays a palette of bright colors, pictures, titles (including ad-hoc titles), and comprehension aids (Figure 1), but unexpectedly lacks the hyperlinks that were present in 2009; that year, in particular, the CEO's review presented a link to the 'Speech' section of the website, where the scripts can still be read online or downloaded in pdf format. Overall, it is possible to record BP's shift towards a more visual-based communicative approach.
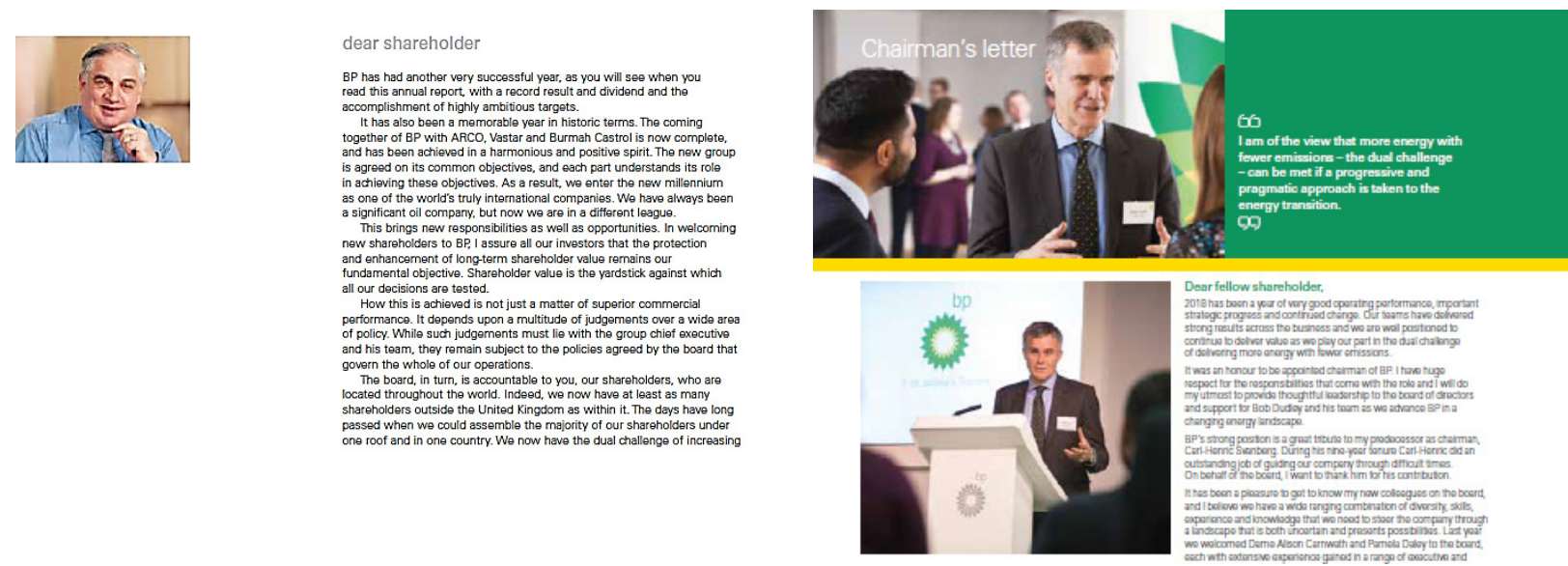

Figure1. Comparison between BP's ACRs - 2000 (left) and 2018 (right)

Similarly, T\&L presents several sections on its website: 'Investors Hub', 'Past Annual Reports', an 'Interactive Annual Report', and a downloadable 'Annual Report'. When compared to the other companies, where the Chairman's statements are generally two pages long (in 2000, 2009, and 2018), the CEO's reviews are five $(2000,2009)$ and four (2018) pages long, and the latter was augmented by comprehension aids.

While these two companies do not seem to have exploited the digital environment to its fullest, others have decided to take advantage of the web-based communication differently. An interesting comparison can be made between BT (British Telecom) and VOD (Vodafone), two companies that operate in the telecommunications sector. The first, BT, has fully embraced the communicative potentialities of the new medium by 
using creative solutions such as, for instance, a single web page to navigate. It opens on an embedded video that bridges age gaps and cultural diversities by introducing the company into ordinary people's lives. Simple activities like playing, cooking, socializing, or enjoying family time convey a familiar atmosphere, thus bringing the company closer to its customers. Users have three types of menu that enable them to search for content on the web page where different sections of the ACR are separately downloadable. BT's 2000 report (129 pages) was rather a formal and plain document where visuals barely appeared; the 2009 ACR, on the other hand, was slightly longer (169 pages) and saw the introduction of colors, whereas the 2018 report (320 pages) is full of pictures of people and landscapes, transforming the formal account into a full visual experience.

The second, VOD, proposes its annual reports in the 'Investors \& Analysts' section that redirects users to a separate page where a sliding menu appears. In the 'Introduction' section, a 'view more' option is available; the introductory paragraph of the Chairman's message is presented (the full message is available by clicking on the 'read more' text box). Besides navigating online, users can download the full pdf in a booklet-like format. However, no major changes may be detected among the three versions in terms of layout or use of visuals.

In 2019, M\&S, like BT and VOD, offered two versions of the ACR: a downloadable pdf and an online review that is less interactive if compared to BT's. In the third section, 'Chairman \& CEO', two short paragraphs report on main points; no extension to the full text, script, or partial pdf download is provided. The 2009 ACR website provided more texts and new-window navigation rather than a scroll down page, as well as a full report of the Chairman's statement (which is still available online). The downloadable pdfs made great use of pictures in 2000 and in 2009, where both the Chairman's statement and the CEO's review were positioned after the financial highlights, but pictures are much less present in the 2019 version, thus conveying a more figure-based and formal approach. In the retail sector, another company, TESCO, opted for placing the 2018 ACR in the 'Report archive' section, where only the pdf is available. Due to its relevance, it must be noted that, a web page including two short videos (entitled 'A short introduction from our CEO' and 'Thoughts from our Chairman') was created for the 2019 ACR. Besides this innovation, it is possible to notice a recurring pattern: users are invited to download the pdf where both the Chairman's statement and the CEO's review (2000)/ Q\&A (2009) / statement (2018) are at the very beginning of each report. ${ }^{7}$ Visuals slightly increase in number but are minimally used.

\section{Conclusion}

7 TES 2000, Chairman's statement p.1/32 and CEO's review p. 2/32; TES2009, p.3/140 and p. 4/140, TES2018, p.3/160 and p.4/160 respectively. 
At first glance, as regards Question 3, ACRs seem to have undergone minimal change in the digital environment; in fact, it is safe to claim that corporate communicators ensure the trust of their readers by uploading the digitally customized hard copy of an ACR's traditional printed version as a mere fulfillment of legal requirements. The analysis of the websites of the companies that was conducted in 2019 and is included in the present corpus showed that, generally speaking, the influence of the web-based communication on ACRs remains limited. Based on the analyzed dataset, which does not permit generalizations about corporate communication per se, it can be maintained that this genre of corporate discourse seems not to have undergone any significant changes, thus basically confirming the trends that had been highlighted both in 2001 and in 2010 .

Nevertheless, some companies' decision to create an online ACR is translated into an abridged, user-friendly disclosure of the ACRs' narratives, thus underlining the document's main aim, which is ultimately to be read by the largest possible audience. The ACRs' sizes tend to increase from medium- to long-lengths. As to Question 1, the companies that exploit the digital environment more prominently allow users to both navigate the ACR online and download a document in a pdf format (that is occasionally interactive) that has gained accessorial elements, such as videos, over time. As to the narrative parts, a twofold approach was implemented: the CEO and Chairman's messages are either reported in their entirety as in the ACR, or are abridged (e.g. M\&S), resulting in a very short summary.

By and large, two main approaches emerge. On the one hand, some companies (BT, VOD) seem to fully exploit the potentialities of the virtual environment by promoting innovation and dynamicity in line with the times - and possibly the industry - they operate in. They openly assign the role of an effective marketing tool to the ACR. On the other hand, some companies (BP, T\&L) seem to under-exploit web-based communication in the name of a supposedly higher level of credibility. Ultimately, though, it is safe to claim (Question 2) that all these adjustments in format that are reflected in the narrative sections of the ACR powerfully contribute to the promotion of a trustworthy company image.

\section{References}

Argenti, P. 2005. How technology has influenced the field of corporate communication. Journal of Business and Technical Communication 20(3): 357-370.

Beattie, V., McInnes, W. \& Fearnley, S. 2004. A methodology for analysing and evaluating narratives in annual reports: a comprehensive descriptive profile and metrics for disclosure quality attributes. Accounting Forum 28(3): 205-236.

Beatty, R. C., Shim, M. \& Jones, C. 2001. Factors influencing corporate web site adoption. A time-based assessment. Information \& Management 38(6): 337-354. 
Bhatia, V. K. 1996. Methodological issues in genre analysis. Hermes, Journal of Linguistics 16: 39-59.

Bhatia, V. K. 2008. Genre analysis, ESP and professional practice. English for Specific Purposes 27: 161-174.

British Petroleum. 2018. Annual Company Report. Retrieved on 30 June 2019 from https:// www.bp.com/en/global/corporate/investors/results-and-reporting/annual-report.html

British Telecom. 2018. Annual Company Report. Retrieved on 30 June 2019 from https:// www.btplc.com/Sharesandperformance/Annualreportandreview/2018summary/

Chalmers, K., Clinch G. \& Godfrey J. M. 2008. Adoption of international financial reporting standards: Impact on the value relevance of intangible assets. Australian Accounting Review 18: 237-247.

Crawford Camiciottoli, B. 2019. Shades of evaluative meaning in web-based company communications: The case of fashion brands, Textus XXXI (1): 19-36.

Ditlevsen, M. G. 2012. Telling the story of Danisco's annual reports (1935 Through 2007-2008) from a communicative perspective. Journal of Business and Technical Communication 21(1): 92-115.

Dunne, P. \& Morris, G. D. 2009. Non-Executive Director's Handbook ( ${ }^{\text {nd }}$ ed). Oxford: Elsevier.

Garzone, G. 2007. Genres, multimodality and the World Wide Web. Theoretical issues. In: G. Garzone, G. Poncini, \& P. Catenaccio (eds), Multimodality in Corporate Communication, 15-30. Milano: Franco Angelo.

Giglioni, C. 2014. Variation in apologetic strategies in annual company reports: Rhetorical function of lexical-syntactical patterns. In: P. Evangelisti Allori, J.A. Baterman \& V.K. Bahtia (eds.), Evolution in Genre: Emerge, Variation, Multimodality, 45-65. Bern: Peter Lang.

Giglioni, C. 2017. Annual reports of the FT30 index members: Deployment of apologetic strategies in CEO and chairman's statements. International Journal of Language and Linguistics 4: 88-94.

Giltrow, J. \& Stein, D. 2009. Genres in the Internet. Issues in the Theory of Genre. Amsterdam/ Philadelphia: John Benjamins.

IFRS, Conceptual Frameworks of Financial Reporting. Retrieved on 25.01.2010 from https:// www.ifrs.org/issued-standards/list-of-standards/conceptual-framework/

Ihator, A. S. 2001. Communication style in the information age. Corporate Communications 6: 199-205.

Istrate, L. G. 2019. International financial reporting standards: A pre-/post-IFRS a d o p tion comparative analysis. The European Proceeding of Social \& Behavioural Sciences, 247-256. 
Madhavaram, S. \& Appan, R. 2010. The potential implications of web-based marketing communications for consumers' implicit and explicit brand attitude: A call for research. Psychology and Marketing 27(2): 186-202.

Marks \& Spencer. 2018. Annual Company Report. Retrieved on 30 June 2019 from https:// corporate.marksandspencer.com/annualreport

Murphy, A. C. 2015. On "True" portraits of Letters to Shareholders - and the importance of phraseological analysis. In: S. Hoffman, B. Fischer-Starcker, A. Sand (eds.), Current Issues in Phraseology, 57-81. Amsterdam: John Benjamins.

Purver, M., Valentinčič, A., Pahor, M. \& Pollak, S. 2018. Diachronic lexical changes in company reports: An initial investigation. 1st Financial Narrative Processing Workshop at LREC, 1-8. Retrieved on 25.02.2020 from https://pdfs.semanticscholar. org/0941/b6aeb383753da8fd861ebdbdd291466343a6.pdf

Rutherford, B. 2002. The operating and financial review: could do better, could say more. Accounting and Business 5 (3): 40-41.

Rutherford, B. 2005. Genre analysis of corporate annual report narratives: A corpus linguistics-based approach. Journal of Business Communication 42(4): 349-378.

Tauringana, V. \& Mangena, M. 2006. Complementary narrative commentaries of statutory accounts in annual reports of UK listed companies. International Journal of Management Accounting Research 8 (2): 71-107.

TESCO. 2018. Annual Company Report. Retrieved on 30 June 2019 from https://www.tescoplc.com/investors/reports-results-and-presentations/reports-archive/

Vodafone. 2018. Annual Company Report. Retrieved on 30 June 2019 from https://investors. vodafone.com/investors-analysts/annual-reports/

Ware, B. L. \& Linkugel, W. A. 1973. They spoke in defence of themselves: On the generic criticism of apologia. Quarterly Journal of Speech 59: 273-283.

\section{$* * *$}

Cinzia Giglioni holds a research and teaching position at the Department of Political Sciences, University of Rome "La Sapienza". She was a contract professor for several years in different universities in Italy, teaching both BA and first level master degree students. Her research interests span from second language acquisition to discourse analysis, especially in the context of LSP research. Her most recent contributions focus on the linguistic aspects of corporate and political communication. She has presented papers at several international conferences and symposia, and has published the results of her research in journals and edited volumes. She regularly collaborates with various international research groups, including CLAVIER (The Corpus and Language Variation in English Research Group) and GERAS (Groupe d' Etude et de Recherche en Anglais de Spécialité). 